\title{
AN INVESTIGATION ON FAILURE ANALYSIS OF TITANIUM GAS TURBINE COMPRESSOR BLADES
}

\section{H. Sepehri AMIN ${ }^{\mathrm{a}}$, A. KERMANPUR ${ }^{\mathrm{a}, *}$, S. ZIAEI RAD ${ }^{\mathrm{b}}$, H. FARHANGI ${ }^{\mathrm{c}}$, M. MOSADDEGHFAR ${ }^{d}$}

${ }^{a}$ Department of Materials Engineering, Isfahan University of Technology, Isfahan 84156-83111, Iran.

${ }^{b}$ Department of Mechanical Engineering, Isfahan University of Technology, Isfahan 84156-83111, Iran.

${ }^{\mathrm{c}}$ Faculty of Engineering, University of Tehran, Tehran, Iran.

${ }^{\mathrm{d}}$ Managing Director, Isfahan Regional Electric Company, Isfahan, Iran.

\begin{abstract}
Several premature failures were occurred in the high-pressure section of an industrial gas turbine compressor due to the fracture of titanium blade roots. In this work, the failure process of the compressor blades was investigated using experimental characterisation methods. Macro/microfractographic studies were carried out on the fracture surfaces. Optical and scanning electron microscopy of the blade airfoil and root were performed. Mechanical properties of the blade alloy were also evaluated and compared with the standard specifications.
\end{abstract}

The experimental results showed no metallurgical and mechanical defects for the blade materials. Microstructures of the blade root and airfoil as well as the hardness and tensile properties were all comparable with those reported in the standard specification AMS 4928Q. Fractography experiments showed clearly multiple crack initiation sites and fatigue beach marks. Debris particles were observed on the fracture surface of samples and in the mouth of initiated cracks. The blade surface in contact to the disc in the dovetail region showed a higher surface roughness than the other surfaces. Based on the results obtained, the fretting fatigue mechanism was proposed for the premature failures. It was concluded that the stress concentration has been caused by either unsuitable curvature ratio of the disk dovetail, incorrect design of the blade or insufficient distance between the blade root and the disk in dovetail region.

Keywords: Failure analysis, Compressor blade, Fractography, Fretting fatigue.

\section{INTRODUCTION}

The phenomenon of 'fretting fatigue' has been recognized and studied well for over a century. Fretting is defined as the wear process occurring between two surfaces that have an oscillatory motion of small amplitude, on the order of tens of microns [1]. It has been responsible for a large number of service failures across a wide range of applications. For 
example, fretting in railway axles was reported by Maxwell et al. [2] in 1967, yet remains a cause for concern in forty years later [3]. For obvious reasons, fretting fatigue is particularly important in safety-critical industries such as aerospace. The recent High Cycle Fatigue (HCF) initiative [4] in the USA has provided a focus for fretting research in the aerospace sector, particularly in aircraft engine applications. These include the 'dovetail' roots of compressor blades (Nowell, [5]), where failure may have serious consequences for engine integrity (Xi et al., [6]). Furthermore, wherever two or more turbine components are in tight contact, fretting fatigue becomes a relevant failure mechanism. In this paper, several premature failures of $\mathrm{Ti}$ alloy compressor blades are characterized. Characteristics of the fretting fatigue mechanism are discussed.

\section{EXPERIMENTAL}

Several premature failures were occurred in the high pressure compressor of gas turbines of a power plant in Isfahan due to fracture of the blade roots. The plant is working under nominal output power $29 \mathrm{MW}$ with the rotating speed $8500 \mathrm{rpm}$ in the high pressure compressor. The failures were experienced at the 9th, 10th, and 12th stages of the compressor. Table 1 lists only the working history of the fractured blades in the 9th stage. First, chemical composition and mechanical and metallurgical properties of the blades were characterized. In order to perform optical microstructural investigations, metallographic tests were carried out on different samples prepared from the root and airfoil of blades. Hardness test on the root and airfoil of the blades was performed using Hauser 292DR machine. Tensile test was carried on the sub-sized specimens, which were prepared from root of blades according to JIS-Z 2201 standard by Instron- 8500 machine. Macro-fractography was performed on the surface of the samples by digital camera. In one of the fracture occurrences, a blade was left inside the disc with a crack in the root region. The fracture surface of the blade was also investigated along with the other completely fractured blades. Micro-fractography studies were carried out on all the failed samples by SEM Philips X230 machine equipped with EDS chemical analysis.

Table 1. The working history of the failed blades.

\begin{tabular}{|c|c|c|}
\hline Failure \# & Date & Working hours \\
\hline 1 & March 2005 & 7653 \\
\hline 2 & May 2005 & 7669 \\
\hline
\end{tabular}

\section{RESULTS and DISCUSSION}

Table 2 shows chemical composition of the blade material compared with the standard limits of Ti6Al4V alloy. It confirms the composition of the fractured blade to be Ti6Al4V alloy. The microstructures of the blade root and airfoil with different working hours are presented in Figure 1. It is consisted of predominantly equiaxed $\alpha$ grains, lamellar transformed $\alpha$ plates, and fine intergranular $\beta$ phases with the percents of $65 \%$ and $35 \%$, respectively. It should be noticed that this microstructure is common in Ti-alloy compressor and fan blades, with equiaxed portion providing good tensile ductility and hence good resistance to crack initiation, while the lamellar portion is responsible for increasing resistance to crack propagation.

Table 2. Chemical composition of the blading alloy.

\begin{tabular}{|c|c|c|c|c|c|c|c|c|c|}
\hline \multicolumn{2}{|c|}{ Bfampositiqean } & 5.18 & 3.51 & $0 \% 5$ & $<M 90$ & $<8.50$ & $<0 ! b_{0}$ & PPd & $88 . \mathbf{i} 6$ \\
\hline Standard & RAD & 5.96 & B.50 & $1-7: 9$ & שע & -- & -- & 0.74 & Red \\
\hline & $\max$ & 6.75 & 4.50 & 0.30 & --- & --- & --- & --- & \\
\hline
\end{tabular}



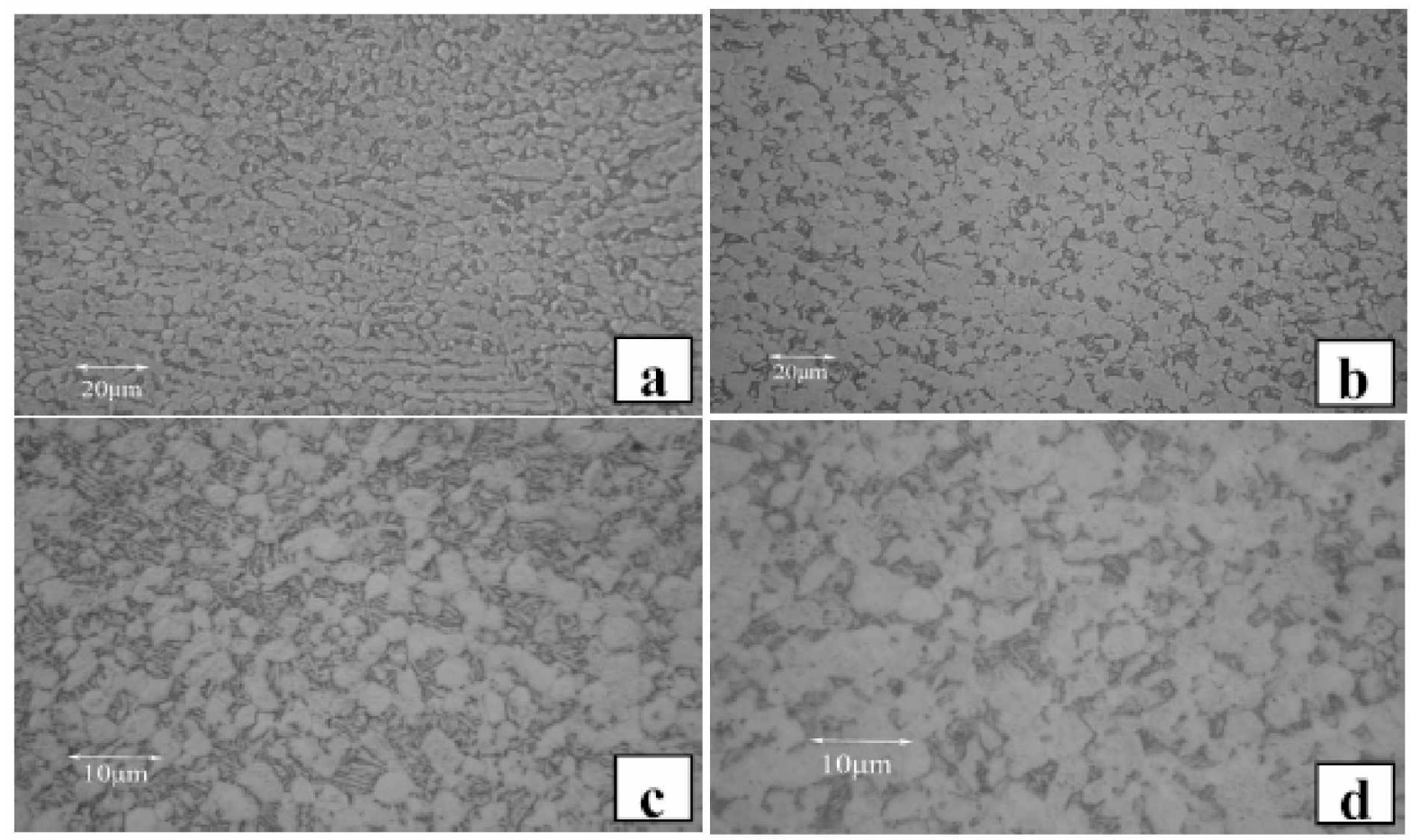

Figure 1. Microstructure of the fractured blades: a,b) root \& c,d) airfoil; $\left.\mathrm{a}, \mathrm{c}) 1^{\text {st }} \& \mathrm{~b}, \mathrm{~d}\right) 2^{\text {nd }}$ fractures.

Hardness values of the root and airfoil of two failed blades are presented in Table 3 . The root and airfoil both had the same hardness. Tensile properties of the samples with different work hours are shown in Table 4. It can be seen that the mechanical and metallurgical properties of the blade material are in the standard range and no deviation in these properties were detected. Figure 2 shows macro-fractography images of the $1^{\text {st }}$ and the $2^{\text {nd }}$ failures. Three different regions are remarkable in each fracture surface. In the first and second regions, beach marks are clearly detectable. Moreover, several radial lines can be revealed in each fracture surface. The position of the main crack initiation in the first region of each fracture surfaces and the angle of propagation from the edge of contact (EOC) are determined (Figure 2). It is seen that the characteristics of the fracture surfaces and the position of crack initiation are more or less similar.

Table 3. Vickers hardness of the blade's root and airfoil.

\begin{tabular}{|c|c|c|}
\hline Number & Position & HV \\
\hline $1^{\text {st }}$ fracture & Airfoil & 359.33 \\
\cline { 2 - 3 } & Root & 335.8 \\
\hline $2^{\text {nd }}$ fracture & Airfoil & 353.25 \\
\cline { 2 - 3 } & Root & 338.17 \\
\hline
\end{tabular}

Table 4. Mechanical properties of different fractured blades.

\begin{tabular}{|c|c|c|c|c|}
\hline Sample & $\begin{array}{c}\text { YS } \\
{[\mathrm{MPa}]}\end{array}$ & $\begin{array}{c}\text { UTS } \\
{[\mathrm{MPa}]}\end{array}$ & $\begin{array}{c}\text { Elongation } \\
{[\%]}\end{array}$ & $\begin{array}{c}\text { Reduction } \\
\text { of Area[\%] }\end{array}$ \\
\hline
\end{tabular}




\begin{tabular}{|c|c|c|c|c|}
\hline Standard (min) & 862 & 931 & 10 & 25 \\
\hline $1^{\text {st }}$ fracture & 961 & 1093 & 11.8 & 39.2 \\
\hline $2^{\text {nd }}$ fracture & 984 & 1025 & 16 & 33 \\
\hline
\end{tabular}
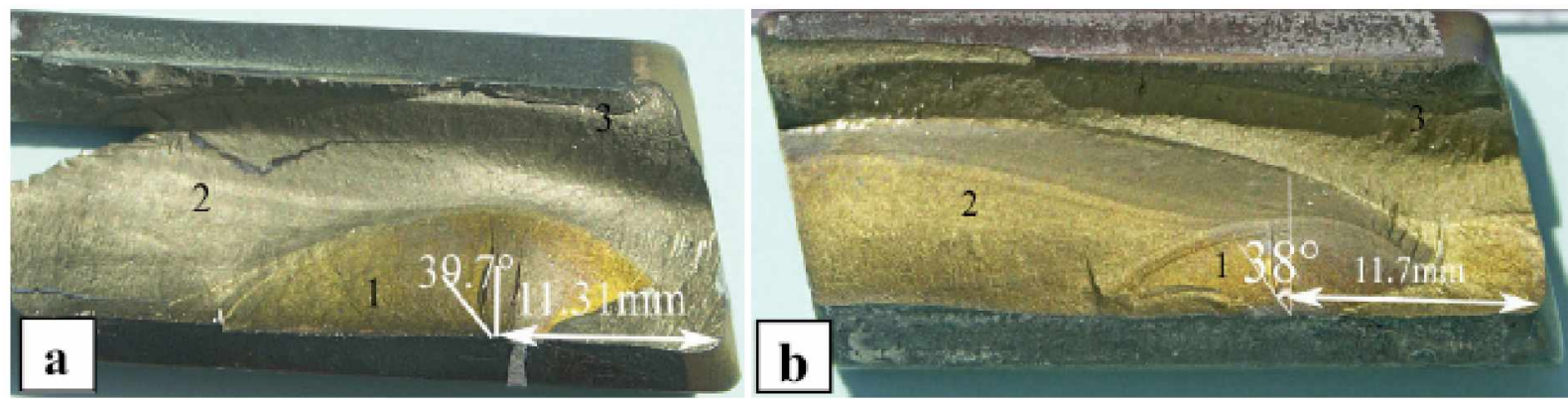

Figure 2. Fracture surfaces of the: a) $1^{\text {st }}$ and b) $2^{\text {nd }}$ failure. Note that three distinct regions are numbered and the main position for crack initiation are identified by an angle.

Micro-fractography tests were performed on different fracture surfaces as shown in Figure 3 for the $1^{\text {st }}$ fracture. Figure 3a shows the main crack, beach marks and radial lines in region 1 of fracture surface. Figure $3 \mathrm{~b}$ illustrates the fatigue appearance in region 2 . The image of EOC and multiple micro crack initiation are observed in Figure 3c. The brittle fracture mode can be clearly seen in the fracture surface as shown in Figure 3d. Many debris particles as an indication of wear were found on EOC and in the mouth of cracks (Figure 4). EDS analysis (Table 5) of the debris particles showed a high amount of oxygen confirming oxidation of $\mathrm{Ti}$ during the service, which is responsible to form abrasive $\mathrm{TiO}_{2}$ particles in the fracture surface.

Table 5. EDS analysis of the blade alloy and debris on EOC.

\begin{tabular}{|c|c|c|c|c|c|c|c|c|c|}
\hline Location & $\mathbf{T i}$ & $\mathbf{A l}$ & $\mathbf{S i}$ & $\mathbf{V}$ & $\mathbf{F e}$ & $\mathbf{M o}$ & $\mathbf{N a}$ & $\mathbf{P}$ & $\mathbf{O}$ \\
\hline Matrix & 89.39 & 7.75 & 0.25 & 2.61 & --- & 1.18 & --- & --- & --- \\
\hline Debris & 32.24 & 5.89 & 2.43 & 1.52 & 2.42 & 1.18 & 0.48 & 0.4 & 52.8 \\
\hline
\end{tabular}

Debris also showed some iron content coming from the steel disk. Sever sliding and rough surfaces were observed in EOC in the blade roots as shown in Figure 5. It is believed that the coating of blade root and disk in the contact region were damaged making these surfaces so rough which can directly influence the crack initiation. The results of roughness measurements are listed in Table 6. As it can be seen, the maximum surface roughness is achieved in the EOC region.

According to all experimental results, existence of multiple crack initiation at EOC, presence of debris in the contact region, severe sliding wear, and high roughness at EOC, proposed that the main reason for failure phenomenon in the premature fractures of $\mathrm{Ti}$ alloy blades is the fretting fatigue mechanism. 


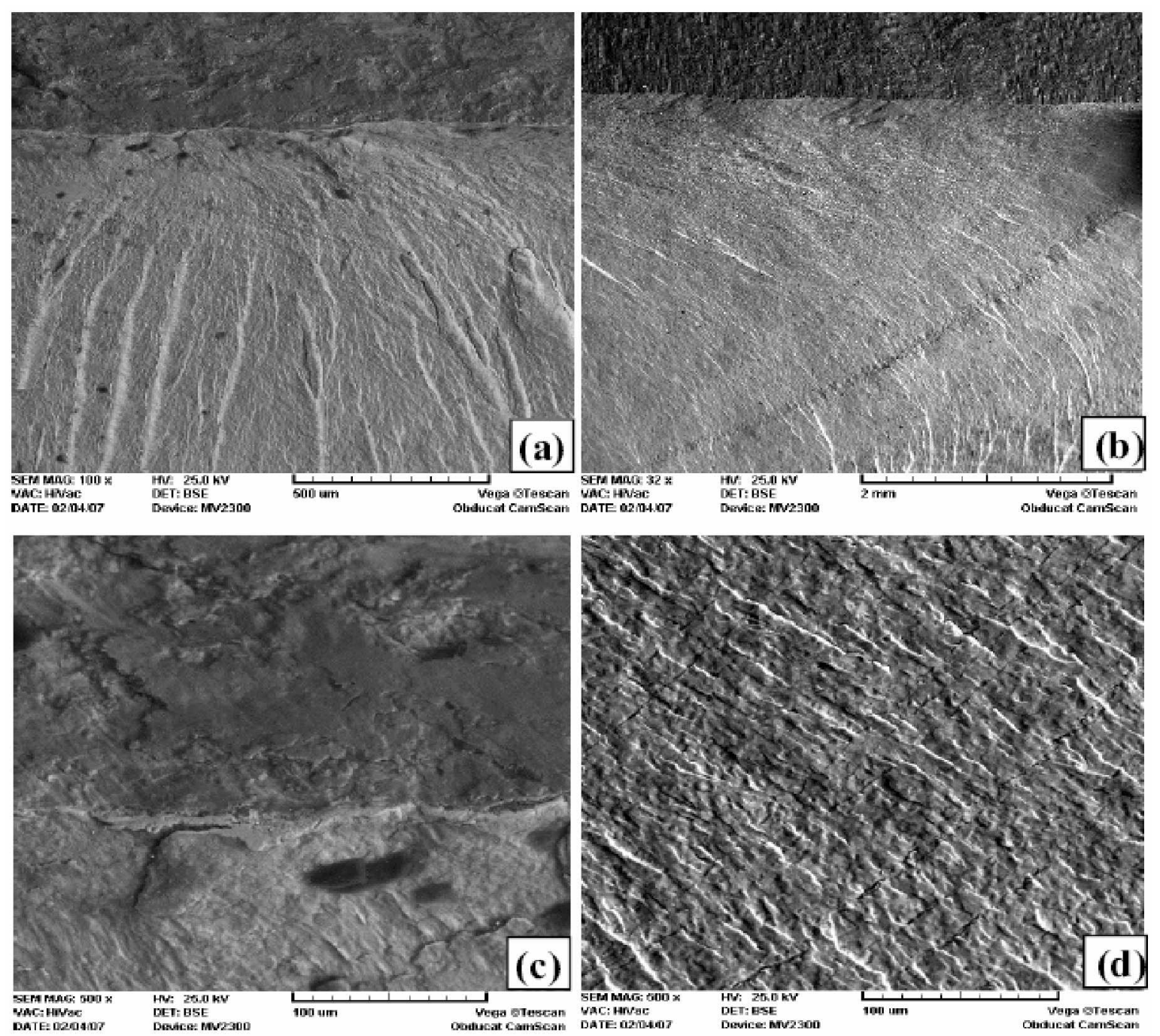

Figure 3. Micro-fractography of the $1^{\text {st }}$ fracture surface: a) region $1, b$ ) transition to region 2 , c) EOC, and d) brittle manner of material.

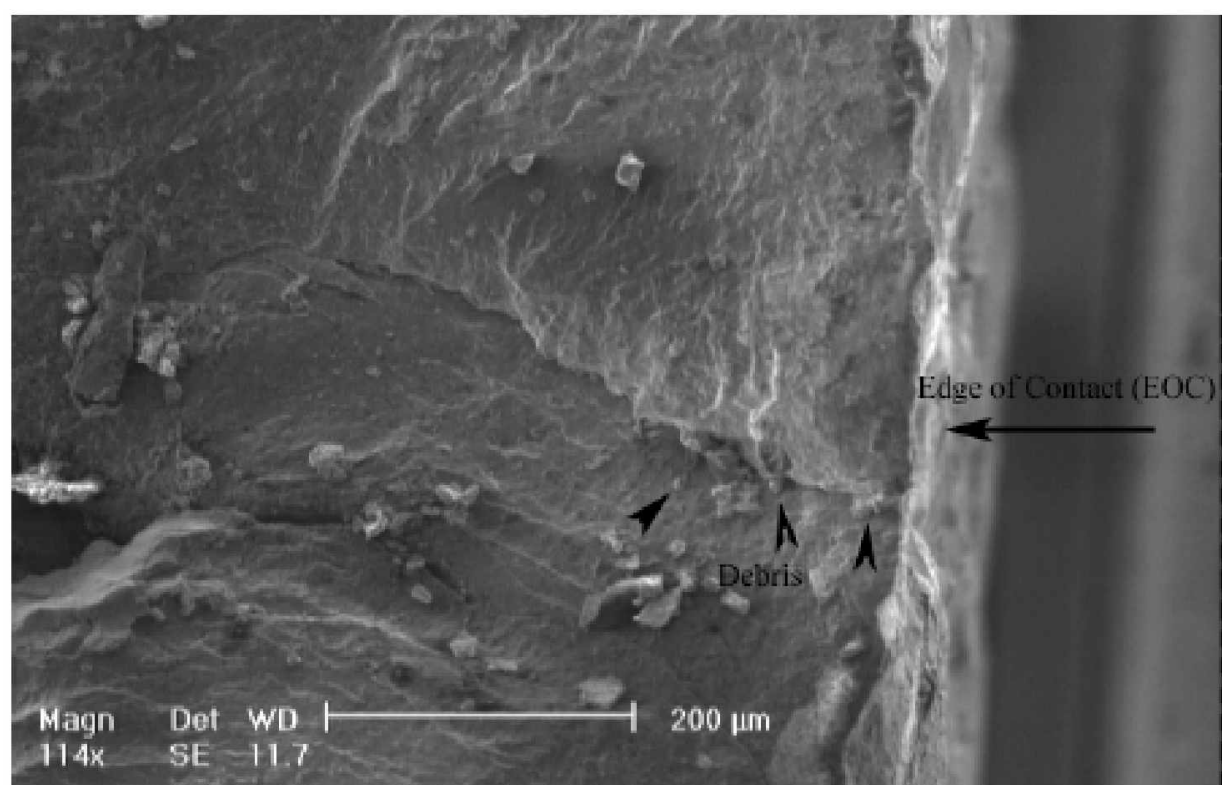

Figure 4. Micro-fractography of the $1^{\text {st }}$ cracked blade fracture surface showing the main crack and debris in mouth of crack. 
Table 6. Roughness at different regions of the blade.

\begin{tabular}{|c|c|c|c|c|c|}
\hline Roughness & $\begin{array}{c}\text { Airfoil } \\
\text { convex side) }\end{array}$ & $\begin{array}{c}\text { Airfoil } \\
\text { (Concave side) }\end{array}$ & $\begin{array}{c}\text { Root, no } \\
\text { contact }\end{array}$ & $\begin{array}{c}\text { Root, EOC, } \\
\text { near crack }\end{array}$ & Root, EOC \\
\hline $\mathbf{R a}_{\mathbf{m}}(\boldsymbol{\mu} \mathbf{m})$ & 0.863 & 0.950 & 1.183 & 2.493 & 3.770 \\
\hline STDEV & 0.09 & 0.06 & 0.15 & 0.94 & 1.98 \\
\hline
\end{tabular}

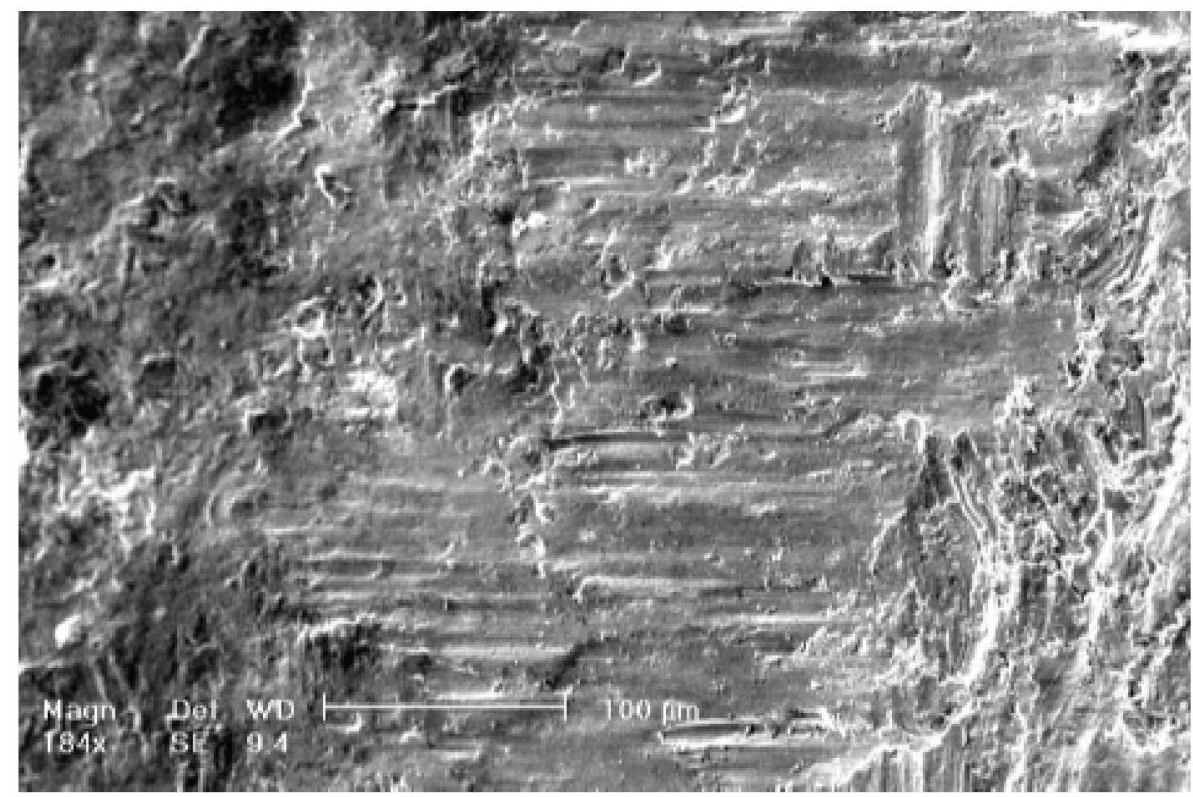

Figure 7. Micro-fractography of the $2^{\text {nd }}$ fracturesurface showing sliding marks on EOC.

\section{CONCLUSIONS}

1. Multiple crack initiation and growth was observed in this failure due to fretting fatigue mechanism.

2. Crack initiation was occurred at the corner on contact facet of blade dovetail between blade dovetail and wheel dovetail.

3. The metallurgical and mechanical properties of the balding materials were all accepted according to the relevant standards.

4. It was concluded that the stress concentration has been caused by either unsuitable curvature ratio of the disk dovetail, incorrect design of the blade or insufficient distance between the blade root and the disk in dovetail region. The above mentioned factors as well as abnormal vibration has caused the fretting fatigue failure.

\section{ACKNOWLEDGEMENTS}

The authors would like to acknowledge Isfahan regional electric company for financial support of this work under contract 100/31911-113.

\section{REFERENCES}

1. Hutson, A.L. et al.," Effect of various surface conditions on fretting fatigue behavior of Ti-6Al-4V

" Int. J. Fatigue, 24 ,2002, pp.1223-34.

2. Maxwell, W.W. et al., Proc. I. Mech. E, 182 ,1967, pp.89-108.

3. Hirakawa, K. et al., Int. J. Fatigue, 20, 1998, pp.135-144.

4. Burns, C., Proc. $7^{\text {th }}$ Nat. Turbine Engine HCF Conf., Dayton, Ohio , 2002. 
5. Nowell, D.," RECENT DEVELOPMENTS IN THE UNDERSTANDING OF FRETTING Fatigue", Proc. Prog. in Structural Mechanics, Univ. of Seville, 61,2000.

6. Xi, N.S. et al., Engineering Failure Analysis, 7, 2000, pp.385-392. 